\title{
Profile of Australian Library Technician Students
}

\author{
By
}

\section{Mary Carroll}

\section{Brief Bio}

I am a teacher in the Library and Cultural studies Department at Victoria University in Melbourne. I am also undertaking a PhD through the School of Information Management at Charles Sturt University in NSW investigating Library Technician education in Victoria

\begin{abstract}
As part of ongoing research into Library Technician education, statistics were gathered specifically related to Australian participants in the Diploma of Library and information Services Training Package for the year 2002. Data was gathered relating to age, gender, education background and employment status of this student cohort. The profile of the Library Technician student was then compared with the broader training package student cohort to examine any similarities or differences particular to Library Technician students. It is the intention that a further comparison will be made at a future date between the 2002 Library Studies cohort and a group of Library Technicians who have chosen to pursue a Librarianship qualification.
\end{abstract}




\section{Profile of Australian Library Technician Students}

The world is full of opinions concerning the people who work in libraries. They range from an inspiring, if a little flowery perception such as that of Miles Harvey who called librarians 'heroic guardians' at war with the forces of oblivion'! (Harvey, M. 2001 pp.113-114) to the more common stereotypes of the pearls, twin set and glasses variety. Those of us who work in the library world have a few perceptions of our own about who its inhabitants are, not least of these being about the library technician. Many statements are made concerning the age, gender, intellectual and educational level of those who undertake Library Technician training in Australia. In 1963, Edward Flowers, a prominent Australian library commentator, had this to say about the emerging paraprofessional library workforce

The workforce will, to some extent, consist of very able women who, having the good sense to realize that their working life is likely to be limited, wish to start working life after matriculation, not after spending four years in higher education. This I would argue is for the common good. Their profitable working life is extended for 4 years. (Flowers, 1963 p.5)

W.L. Brown remarked in 1970:

...most of the students for the Technicians Course would be of a practical rather than academic turn of mind and would have no interest in further study (Brown, 1970

p.112)

The LIS industry has to some extent moved on from this view, yet if you were to ask those involved in the industry today to describe who makes up the Library technician student body, the response would possibly be couched in terms of startlingly similar perceptions. That is: Female, returning to the work force after a career break, over 30 , a career changer, an early school leaver and perhaps not 'academic' enough to undertake a professional qualification. This response persists despite many changes in society and in the structure of Library technician education to include fulltime students and school leavers with the entry requirement being the completion of the final year of high school. These perceptions are well worth interrogating to establish their validity.

Vocational education statistics are gathered nationally in Australia at the point of enrolment and compiled by the Australian National Training Authority (ANTA) with the assistance of National Council for Vocation Education Research (NCVER). These statistics include data from the public training organizations such as Technical and Further Education colleges (TAFE) and give an holistic snapshot of the makeup of the Vocational Education and Training sector (VET) in Australia through publications such as Australian Vocational Education and Training, Students and Courses 2002: In detail. (NCVER, 2003) From these broad statistics concerning all VET students we know that 1.69 million students were enrolled in the sector in 2002 of whom $90.5 \%$ studied part time, $51.9 \%$ were male and $48.1 \%$ were female. In terms of age, $22.2 \%$ were 19 or under, $16.8 \%$ were 20-24, 40.6\% were 25-44 and 18.7\% were 45-64. (NCVER, 2003) Similar statistics for 2003 reveal only minor variations to these statistics. This provides a simplistic overview of the sector as there are major variations in the make-up, age and education level of participants when industry to industry and training level to training level comparisons are made. For example, in the engineering field, $94.6 \%$ of all participants were male, while the level of qualification enrolled in is generally an indicator of previous highest level of education; the higher the qualification; the higher the education level at entry (Teese, Polesel and Walstab 2000 p.3); this is a vastly different picture than given by the broader perspective and is particularly relevant to Library Technician students as most enrol at the higher end of the qualification spectrum; that is Diploma level.

Since 1999 education for the Library Industry in Australia within the public training providers such 
as TAFE colleges has been directed by the introduction of Training Packages. Training Packages have been developed by organizations representing a particular industry. In the case of the Library Industry CREATE Australia (Cultural Research Education and Training Enterprises Australia) has been the responsible body. These organizations are responsible for consulting widely with the industry group in the developing and modification of the specific training package. In 2002 there were 838,000 people enrolled in training packages nationally which made up $41 \%$ of total VET enrolments in Australia. The Library Technician training package comes under the title of Museum and Library/information Services Training Package. In 2002 there were 3,169 individuals and 180 trainees enrolled in this training package, making up $0.4 \%$ and $0.1 \%$ respectively of total training package participants in Australia (NCVER, 2004, p.22.) The following statistics will not include the small cohort of trainees. From this we can see that the Library Technician training sector is very small in relation to overall Training Package numbers in Australia and even smaller in relation to the total number enrolled in VET. The question still remains, who were these participants?

As part of broader research into Library Technician training in Australia statistics were compiled about who was enrolled in Library Technician course nationally. While these statistics were requested early 2004 , due to delays in compiling such information the latest statistics available were those of 2002. With the assistance of Stuart Varney, Project officer from the NCVER (personal communication $11^{\text {th }}$ March 2004), statistical data from that year's enrolment was obtained and tabulated. The information of interest was fairly specific. It included age, gender, highest educational level obtained prior to commencing a library technicians' course and employment status at time of commencement. From this raw statistical data it is possible to begin to develop a profile of who the typical Library technician student really is and a picture of how he or she compares with the total cohort of training package participants. In the current stable education climate one would expect little variation in the make-up of this group thus allowing us to extrapolate the validity of these statistics despite the time lapse. In gaining an understanding of who these students really are we have a snapshot of this cohort and can come to terms with some of the myths and realities which abound about this particular training group. No attempt will be made to critically analyse and evaluate the implications of this data at this stage.

\section{State Enrolment Figures}

If we divide the Library and Information Services and Training Package figures into state of origin we find that Victoria has by far the largest number of training participants, making up nearly one third of the national training output in Library and Information Services and South Australia the least. Despite relative population differences Victorian figures suggest a much more robust training environment in terms of enrolments than the other states. Without further research it is uncertain whether this results from employment demands in Victoria, specific targeted state government policy or is due to other historical forces

TABLE 1

Total number of Library and Information training package enrolments 2002 by Australian state

\begin{tabular}{|c|cccccccc|c|}
\cline { 2 - 10 } \multicolumn{1}{c|}{} & $\begin{array}{c}\text { New South } \\
\text { Wales } \\
\text { State }\end{array}$ & $\begin{array}{c}\text { Victoria } \\
\text { (Vic) }\end{array}$ & $\begin{array}{c}\text { Queensland } \\
\text { (Qld) }\end{array}$ & $\begin{array}{c}\text { South } \\
\text { Australia } \\
\text { (SA) }\end{array}$ & $\begin{array}{c}\text { Western } \\
\text { Australia } \\
\text { (WA) }\end{array}$ & $\begin{array}{c}\text { Tasmania } \\
\text { (Tas) }\end{array}$ & $\begin{array}{c}\text { Northern } \\
\text { Territory } \\
\text { (NT) }\end{array}$ & $\begin{array}{c}\text { Australian } \\
\text { Capital } \\
\text { Territory } \\
\text { (ACT) }\end{array}$ & Australia \\
\hline Total & 499 & 962 & 380 & 165 & 366 & 366 & 263 & 168 & 3,169 \\
\hline
\end{tabular}

\section{Gender}

What of the idea that this group is largely female? The LIS student body was found to be $86 \%$ female and $14 \%$ male, strongly reflecting the common belief about this group. However the ratio of male to female varies from state to state. Males make up a total of $21 \%$ of enrolment in NSW, $14 \%$ in Victoria, with South Australia having the lowest percentage enrolment of males with $7 \%$.The 
break down state by state in terms of actual numbers can been in the following table.

TABLE 2

Gender distribution of TAFE LIS students 2002 by state

\begin{tabular}{|l|rrrrrrrr|r|}
\cline { 2 - 11 } \multicolumn{1}{c|}{} & NSW & Vic & Qld & SA & WA & Tas & NT & ACT & Australia \\
\hline Male & 106 & 132 & 48 & 12 & 58 & 62 & 23 & 18 & 459 \\
Female & 393 & 830 & 332 & 153 & 308 & 304 & 240 & 150 & 2,710 \\
Unknown & 0 & 0 & 0 & 0 & 0 & 0 & 0 & 0 & 0 \\
\hline Total & 499 & 962 & 380 & 165 & 366 & 366 & 263 & 168 & 3,169 \\
\hline
\end{tabular}

A graphic representation of the total number of participants shows that it is a largely, though not exclusively, a female student body. This will come as little surprise given the generally understood composition of the LIS workforce.

\section{GRAPH 1}

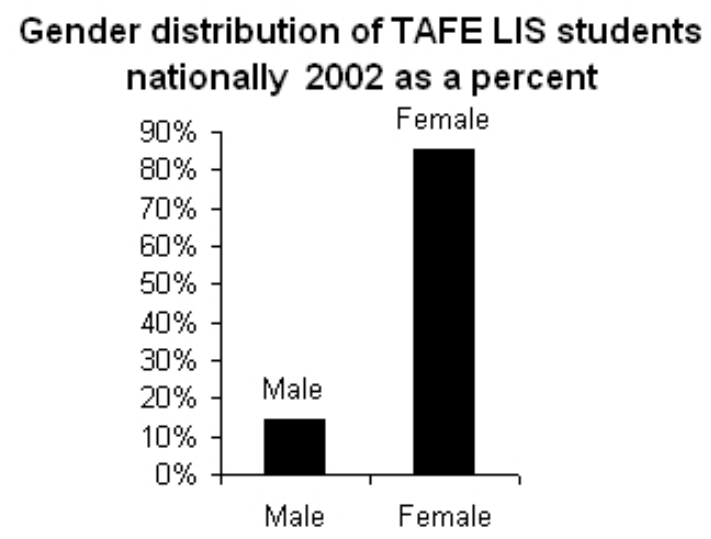

When we compare this percentage to training package participants as a whole we see that LIS students are different in this regard from the average training package student.

\section{GRAPH 2}

\section{Comparison of LIS and all training package participants by gender 2002}

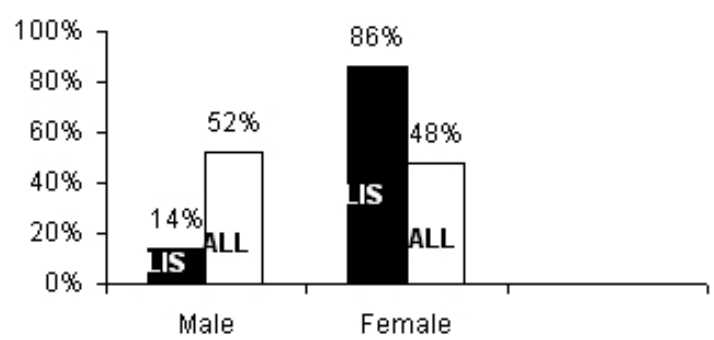

This figure is a little misleading as once again the level of the qualification demonstrates significant variation in the ratio of male to female enrolled. Accordingly

Males were more likely than females to be studying at AQF level III, while females were more likely than males to be studying at AQF diploma level or higher (NCVER, 2004, p.13)

The Library Technician qualification is an AQF (Australian Qualification Framework) Diploma level qualification. These qualifications range through Certificate I, II, III, IV, Diploma and Advanced Diploma. 
Age

What about the view that most library technician students are middle-aged women returning to the workforce? Once again statistics indicate that there is truth in this perception. Approximately $70 \%$ of all LIS training package participants were over the age of thirty, though thirty could hardly be classed as 'middle-aged'. More compelling, however, is the fact that the data reveal that nearly one third or $33 \%$ fell between the ages of $40-49$. This view should be balanced with the fact that nearly $30 \%$ were under the age of thirty, not an insignificant number with about $7 \%$ falling into the school leaver age.

\section{GRAPH 3}

Age of library and information services students 2002

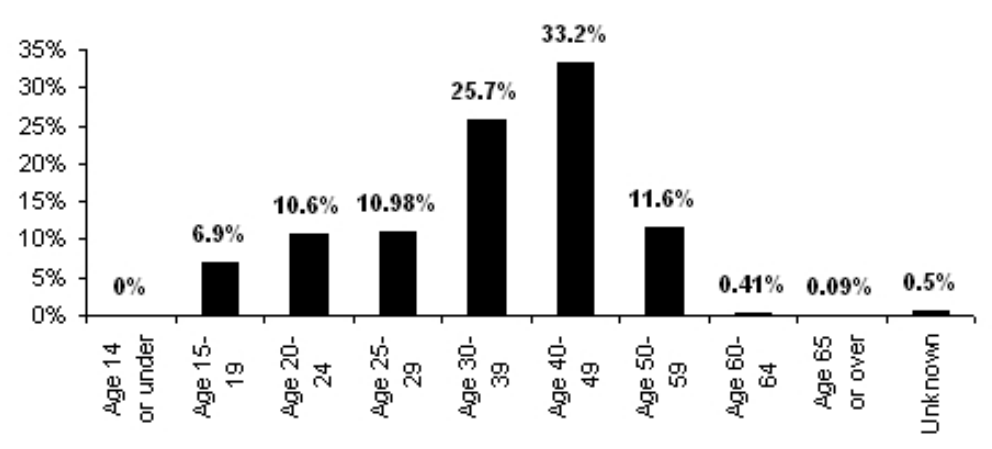

\section{EDUCATIONAL LEVEL}

Another belief about Library Technician students is that they are less academically able, are early school leavers, or they are a combination of both, compared to their university counterparts. The belief that early school leaving is an indication of a person's academic capabilities needs examination. It also presumes that Diploma and Advanced Diploma courses do not require a degree of academic competence. These perceptions themselves seem to come about largely as a result of VET entry policies, which allow for mature age entry at eighteen, circumventing to some extent the rigid entry requirements of universities based on academic performance. TAFE has had a particular mission which, according to educator Batrouney:

... was about the amelioration of disadvantage, eclectic curricula, nation building, citizenship, utilitarian outcomes. (Batrouney in Rushbrook , p. 2, 1997)

With this mission VET institutions set about establishing opportunities for those who would otherwise be denied a post-secondary education.

Failure to complete secondary education or to achieve academic success may be due to factors other than academic ability. Disadvantage, social mores, economic status, life choices and even concepts of gender roles may all have a role in a person's educational outcomes. We also need to consider Australia's many migrants who seek to start their retraining in Australia in the VET sector. They often have qualifications in their own country that are not recognized elsewhere which does not indicate lack of academic ability but rather social and cultural issues. These factors, as well as perhaps lack of confidence or financial constraints, given the increasing cost of university education, may influence choices about where to start, or continue post-secondary education, rather than lack of academic ability. This is evidenced by the continual flow and success of graduates of the VET sector into the university sector. According to one study of Western Australian Library Technician students articulating into a Western Australian librarianship course Library Technician graduates had a lower attrition rate, a higher course completion rate and a slightly higher mean average mark than non-library technician graduates.(Richardson 1999 p.62, p72) Success there would not, we can only assume, be possible without the necessary ability. One other factor also worth considering is the articulation of university graduates into the VET sector. 
For some time now, movement has flowed in this direction with many Training Package participants entering these courses with a prior tertiary qualification. The extent to which training package participants have had prior post secondary experience is not often noted yet it is quite possible for a graduate of a library technician's course to have an undergraduate or post graduate degree and then complete a two year TAFE diploma. This has obvious implication for our perception of ability. So what do the statistics tell us about the educational background of the 2002 group of LIS students?

\section{GRAPH 4}

Highest education level of LIS TAFE students 2002

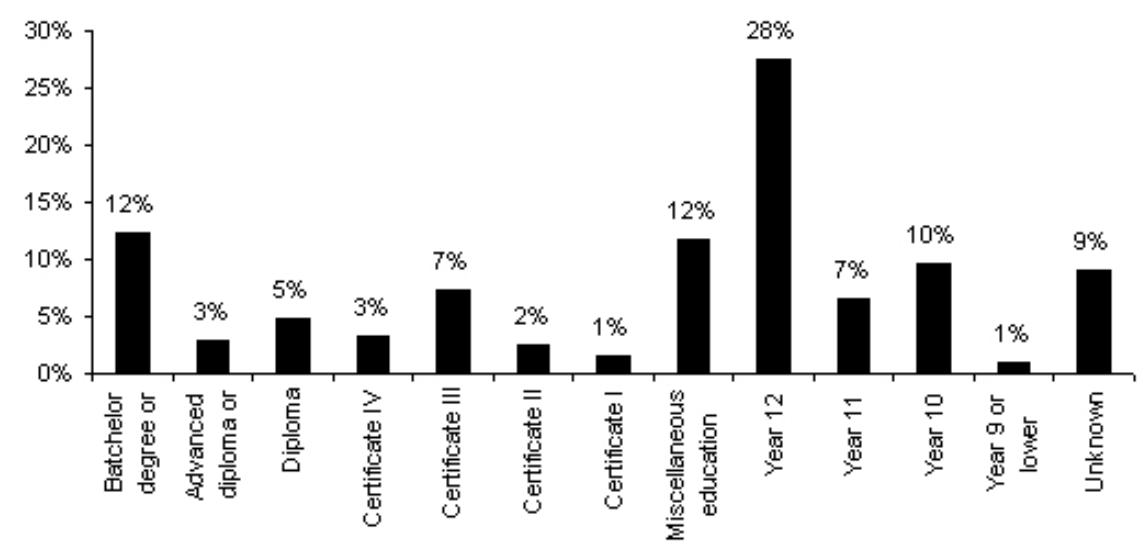

What the graph tells us is that thirty-three percent of these students have a prior known qualification including twelve percent with a bachelor's degree or higher. It also tells us that at least twenty-eight percent completed the final year of secondary school with the assumption that a large number in the Bachelor's degree or higher students also completed this year making allowances for those graduates who entered university under other circumstances such as mature-age entry or perhaps articulation from another qualification. How do the Library Technician students measure up against other training package participants and VET sector participants?

\section{GRAPH 5}




\section{Comparitive education levels of All Tafe, all TAFE Training package and LIS TAFE students}

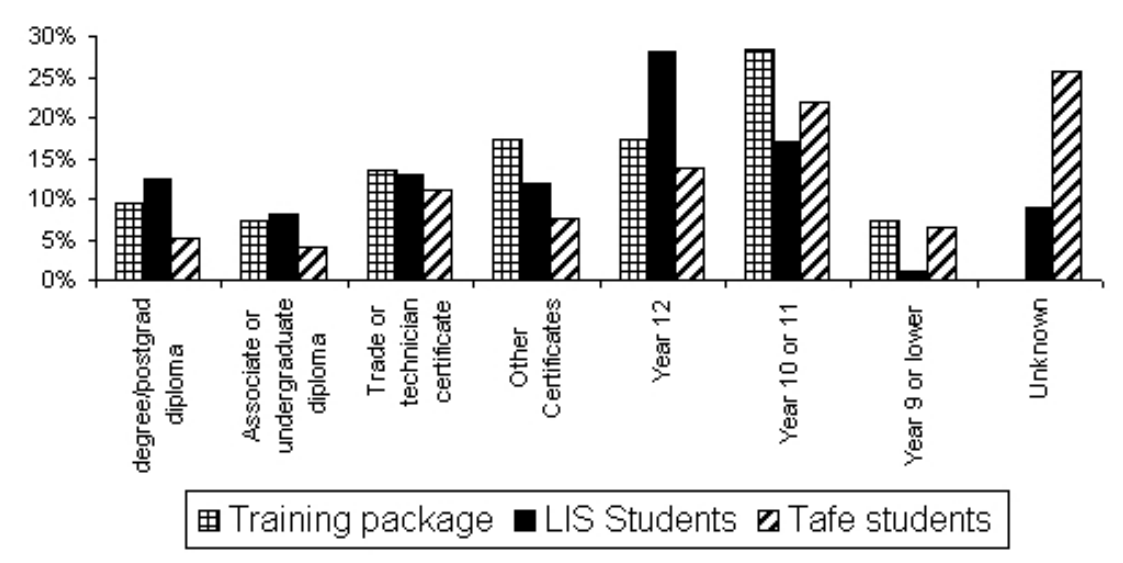

We can see from the above graph that LIS students are more likely to have completed the final year of secondary school, more likely to have a degree or diploma and much less likely to have left school at the earliest school leaving age than either of the other groups. What it does not tell us about is the academic potential of these students. Combining the issues of gender, age and education levels can lead us to some conclusions about why the VET sector is a starting point for these students in their experience of post-secondary education. If we were to include additional issues such as economic status and English as a second language we could further examine some of the forces other than academic ability at work here. The range of academic qualifications is very broad in this sector but with the exception of the Richardson study, we know little about actual ability. What we do know is that many LIS VET students choose to go on to study at the professional level successfully. Take this quote from Roy Sanders, Senior Lecturer in Library and Information Management at Charles Sturt University largely supporting the findings of Richardson (1999) mentioned previously with regard to attrition, completion and academic attainment

A study of the intakes in 1997, 1999 and 2000 shows that the success rate in their first semester of library technicians upgrading was slightly higher than the average for the intake. In fact, in the 1997 and 1999 intakes, not one technician graduate terminated their studies at the end of the first year, compared with up to 17 per cent of those who had no prior tertiary or TAFE study." (Sanders, 2001, p.159-160)

. This remains a complex issue warranting further exploration.

\section{Employment Status}

What of the employment status of those who are enrolled in the Library Technicians training package? In training packages generally, the level of employed participants was around seventy-five percent; those unemployed made up about eighteen percent; while those not in the labour force just under ten percent. (NCVER, 2004 Figure 4 p.12) The figures for LIS training package participants were broken down further than this to include self-employed and those who considered themselves to be partially unemployed. This break down makes it a little more difficult for us to compare status. We are able to say from this that while many of the LIS students may be part-time because of employment commitments, an equally large number may in fact choose to study full time or part time while not being employed. It does support the view of the Library Technician student often being part-time though for a variety of reasons, and in a variety of contexts not just the traditionally attributed ones. 


\section{GRAPH 6}

Employment status of LIS Technicician students 2002

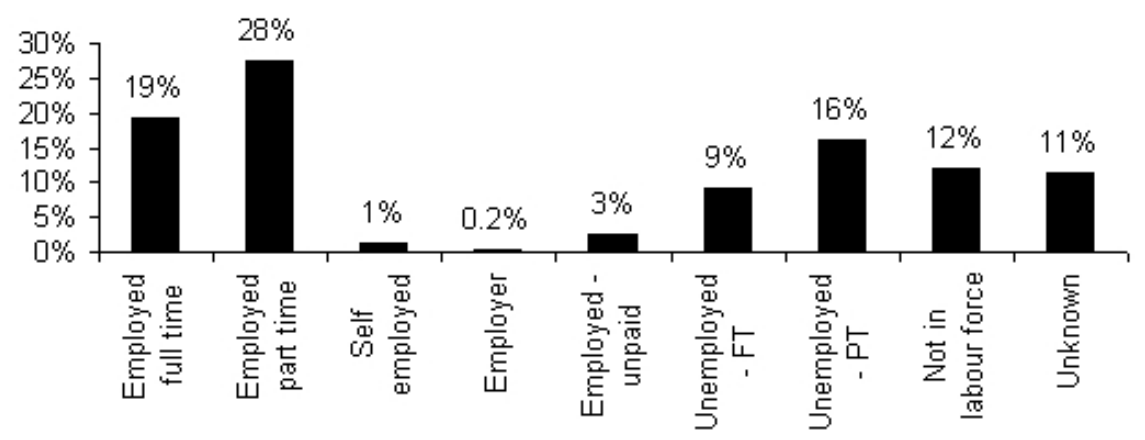

\section{Summary}

Who then is the Australian Library Technician student? If we were to draw a word picture it would be of someone who very much fits the common industry perceptions, at least to some degree. Chances are they would be female and have roughly a $60 \%$ chance of being between 30 and 50 . Less likely are they to be returning to the workforce and to be early school leavers. In some cases they would meet few if any of these generalizations. A library technician student could be male, have a Bachelor's Degree, and be under 25 and employed full-time. There is no doubt that the nature of VET allows for a wide spectrum of student types, bringing to the occupation a vast array of experiences, life and employment skills, generational views, educational outcomes and expectations. It may mean that the course is the first step on the professional path, a new direction in career or life, a conscious effort to gain access to the university sector or a return from generalized education to career focused training. This variety makes for a vital, varied and broad student body that will enter their chosen occupation bringing this with them.

\section{References}

Brown, W. L. (1970). Training for sub-professional library staff in Victoria. Australian Library Journal (April), 109-112.

Flowers, E. (1963). Objectives of training for library service. Australian Library Journal （March), 3-10.

Harvey, M. (2001). The Island of Lost Maps. London: Orion.

NCVER (2002). Student Outcomes Survey National report: Australian Vocational Education and training statistics 2002. Leabrook: Australian National Training Authority.

NCVER (2004). Australian vocational education and training statistics training packages. Adelaide: Australian National Training Authority.

Richardson, C. (1999). The effects of Tafe/University articulation on the education of librarians in Australia. Unpublished master's thesis, Curtin University of Technology, Perth, Western Australia..

Rushbrook, P. (1997). Tradition, pathways and the renegotiation of Tafe identity in Victoria. Discourse 18 (1), 1-12.

Sanders, R. (2001, August). " It seems like an odyssey: upgrading to a professional qualification." Paper presented at the 11th National Library technicians conference, Hobart, Tasmania.

Teese, R., J. Polesel, et al. (2000). Who studies VET and who does not? Brisbane: Australian 
National Training Authority. 